\title{
Effect of Oral Corrective Feedback on Language Skills
}

\author{
Radiah Alsolami \\ Najran University, Saudi Arabia
}

\begin{abstract}
Corrective feedback is an important element in the language learning process. The issue of corrective feedback in language classrooms has been investigated by numerous scholars who believe that the strategy can effectively be used to improve the language skills of students. Though many forms of feedback approaches are used in learning, oral corrective feedback is the commonly used strategy in teaching languages. This is mainly because it captures the diverse elements of language lessons such as pronunciations and spelling. Oral corrective feedback presents a broad field which assists both teachers and students in error identification and eradication. It mainly focuses on highlighting the common errors and mistakes and addressing them enabling the students to avoid them in the future. This paper mainly explores the impact of oral corrective feedback on the language skills of learners. It generally analyses articles that address the issue of oral corrective feedback and derives information regarding the impact of the strategy in language learning outcomes.
\end{abstract}

Index Terms - corrective feedback, oral, language skills

\section{INTRODUCTION}

Sounds are quite essential in communication and language tutors are expected to take a central role in ensuring that their classes effectively learn the pronunciations of different words. Language is highly influenced, and a person who lacks pronunciation skills in a certain language cannot communicate effectively. Moreover, lack of sufficient pronunciation knowledge makes a person unable to encode or decode the intended message appropriately. Different languages have varied phonological systems which cannot be overlooked as that may lead to misunderstanding and unintelligibility. Corrective feedback is an approach that is widely used by language teachers to evaluate and reflect on the progress of the learners with regards to utterances and pronunciations (Zhao, 2015). This strategy is also used to decimate language errors as well as give insight into how students can eradicate such mistakes. Corrective feedback is commonly described as the verbal response which is used by a tutor or addressee to correct erroneous pronunciation or utterances of a speaker. It fundamentally seeks to correct phonological, syntactic, semantic or functional incorrectness that may present in the speech of a speaker. This study primarily aims at expounding on the effects of corrective feedback in the language skills of a learner.

\section{LITERATURE REVIEW}

Corrective feedbacks are normally subdivided into various types whereby each has its appropriate functions. Corrective feedback plays a central role in learning as it highlights the mistakes made by a learner enabling them to eradicate such errors in the future. The use of corrective feedback to facilitate learning begins in early childhood whereby mothers and caregivers correct the young child when they commit mistakes in their speech. At this age, children normally have pronunciation problems and the primary approach used is repetition. Children learn how to speak through repeating after their mothers (Solikhah, 2016). Similarly, teaching a foreign language to adults requires extensive use of oral corrective feedback. Though the essential language skills are attained through practice, provision of appropriate feedback fastens the learning process and enhances proper understanding of various concepts of a language such as pronunciations. Notably, similar corrective feedbacks are used in language learners regardless of age and level of knowledge. Essentially, an adult learning a new language has great similarities with an infant learning their mother tongue. Though toddlers may be slow in learning languages due their partially developed mental and reasoning abilities, the process follows similar steps as adult language classes.

However, kindergarten level corrective feedback is usually informal in that it does not adhere to any particular order. This is entirely different from feedback required in senior grades which are characterized by complex disciplines that require the use of both oral and written feedback to facilitate learning. Oral feedback is often provided in the form of sentences that describe the various weaknesses of a leaner as well as highlighting the strengths. Such corrective approaches are normally considered responses to the work of the learner and they generally facilitate improvement (Sobhani \& Tayebipour, 2015). Feedback can also be provided in the form of a score or percentage defining the level of achievement of the learner on a given subject. Such evaluative feedbacks make the learners aware of their progress and general performance in a given subject. However, oral corrective feedbacks are normally not evaluative as they usually aimed at highlighting mistakes made by a learner, thus triggering self-correction. Additionally, oral corrective 
feedbacks are in most cases informal and unrecorded. This is mainly because they involve sounds and phonetics used in a specific language and help in improving the learners' spoken language.

Research conducted on corrective feedback strategies and their impacts on the learning outcomes has obtained different findings. Some of the findings are despairingly controversial, and this has made scholars question the effectiveness of corrective feedback in facilitating second language acquisition. According to Sanavi and Nemati (2014), corrective feedback is not meant to teach the learners' pronunciations and phonetics in a given language, but it is instead aimed at triggering self-correction. This approach suggests that application of corrective feedback should be delayed so that the learners can naturally realize their mistakes leading to self-repair. Sanavi and Nemati (2014) indicate that though error correction might be quite crucial in learning languages, it can bring detrimental effects on the learning progress of second language learners. I analyze the effectiveness of oral corrective feedback on student learning outcomes and expound on the different strategies that are extensively applied. In his article, he outlines the frameworks and efficacy of different approaches including recast, repetition, clarification request, explicit correction, elicitation, and Para lingual signal.

Recast is defined as an approach that corrects speaker's incorrect utterances by changing one or two components without changing the meaning of the phrase. Repetition is yet another effective strategy whereby the teacher repeats the pronouncements of the learner correcting the mistakes. The mistake is highlighted through emphatically stressing on the word (Han, 2002). Another commonly used approach that is discussed in this study is clarification requests whereby the teacher after noticing a mistake in a phrase or pronunciation made by learner states that they did not understand its meaning, therefore, seeking more clarification. This prompts the learner to reconsider their pronunciation and rephrase their statements thus self-correcting their mistakes. Explicit correction is also another oral corrective feedback approach that entails indication of error committed and provision of a corrected version of the phrase or word. This is believed to be one of the most corrective approaches as it highlights the mistakes and gives correction that facilitating better learning among the learners (Mendez, Arguelles \& Castro, 2010). These are some of the oral corrective feedback approaches that have demonstrated its effectiveness in enhancing understanding and the general learning process of languages.

Other researchers believe that the feedback information a language learner receives from their teacher may positively affect the learning process and improve performance. Research carried out on French learners whereby four corrective feedback strategies were used revealed that recasts are the most commonly used corrective approaches. Divergent feedback approaches such as elicitations, repetitions, and clarification requests found to be more effective in triggering the learner-generated repair of pronunciation mistakes (Lyster, Saito \& Sato, 2013). Ideally, the study established that indeed some feedback approaches enhance the learning of the basics in languages and pronunciation. Moreover, many researchers believe that corrective feedback leads to the development of healthy teacher-student interaction which is quite essential in language classes. Corrections in the learning process have also been believed to play a facilitative and constructive role.

Feedback in oral studies can be done in several ways which mainly depends on the level of understanding of the learners as well as the preferences of the teacher. One of the approaches entails recording all mistakes that students have made and analyzing these mistakes with the entire class. For instance, the teacher can write correct and incorrect phrases and ask whether the students notice any error in the two sentences. This does not only enable the teacher to correct the students, but it also serves as an assessment which allows the teacher to know the progress of the students language comprehension. According to Sermsook, Liamnimitr and Pochakorn, (2017), it is essential that teachers anonymously correct students who make mistakes. Revealing the students who made these mistakes can be quite discouraging to students and can inhibit learning. Another study discusses the importance of discretion in handling student's mistakes. According to this research, oral corrective feedback can have a negative impact on the learning process especially when the teacher uses the approach as a way of evaluating students. This article states that the best way of giving oral corrective feedback is by providing it as a response to the students' work. For instance, if a teacher notices a problem with a student's pronunciation, then he/she should provide oral corrective feedback while at the same time acknowledging the efforts of the student (Penning de Vries et al., 2010). Outright rebuking of students defeats the purpose of the oral feedback provided and adversely affects the learning progress of a student. instructors should always give insight on how a student can improve their speech and written language from a neutral point. The process of providing oral corrective feedback should be carried out systematically in stages whereby the learners should be given time to self-correct their mistakes. Oral corrective feedback should only be provided if the students are unable to selfcorrect and after its provision, the teacher should access the level of understanding and give all clarifications that might be needed.

Sheen (2010) claims that researchers have long argued about the effects of feedback on learning outcomes. The development of intelligible language skills should be a primary concern for teachers. The article acknowledges that language learning is usually characterized by mistakes which include pronunciation and even spelling. As much as learning the correct pronunciation of words in a given language, it is also quite important that the students learn how to correctly spell the words as well as how to effectively communicate using the language. Sheen (2010) explores different feedbacks which are necessary for the process of learning language; written and oral. Ideally, students have different perceptions of different feedback approaches. Moreover, each of the feedbacks aims at correcting distinct types of 
mistakes in languages. For instance, written feedback can only correct spelling and grammar mistakes, while oral feedback mainly focuses on the correction of pronunciation/phonetics mistakes. According to Loewen and Erlam (2006), the effectiveness of any of the corrective feedbacks primarily depends on the perception of the learner, and it is, therefore, necessary that teachers consider the views of the students regarding feedback and error correction and integrate them into their teaching strategies to achieve optimum learning.

Timing is another factor that scholars suggest effectiveness of oral corrective feedback. According to Phillips (1992), the corrective feedback should be provided within a specific time for it to have a positive impact on the learning process of a student. This raises a question of whether corrective feedback should be provided immediately after a mistake is noted, after provision of instruction or immediately learners are exposed to a varied lingual structure. Ideally, some of the errors made by language learners are developmental which simply means that they are committed due to the poorly developed language system in an individual. Such errors are automatically eradicated as the learner gains more understanding of the language. This is quite similar to the process of toddlers learning their mother tongue whereby they self-correct their mistakes as they get a better understanding of the language (Ellis, 2010). Notably, internalization of linguistic knowledge takes time, and it is therefore highly advisable that to only provide corrective feedback to language learners when they make mistakes that are irreparable. For effective learning, it is advisable that errors are corrected during the task. This is generally known as online corrective feedback while feedbacks provided after completion of tasks are termed as offline feedbacks. Both online and offline correctional feedback can focus on a particular linguistic target or a variety of linguistic features.

Online oral corrective feedback creates opportunities for interaction between the learner and teacher thus facilitating better learning. This approach allows for immediate analysis of wrong and right forms of the phrases in question. It is an ideal approach which enables objective language teaching positively impacting on the learning outcomes of the students. Pfanner (2015) as opposed to the online provision of corrective feedback as it is at this time when learners can contextualize form-focused instruction without having to focus on a particular linguistic structure. The author argues that feedbacks provided during the task prompt learners to only focus on the highlighted mistakes thus failing to understand other elements that the task might entail. For instance, if a leaner is reading a passage, and the teacher gives correction whenever he/she mispronounces a word, it is likely that the learner will focus on avoiding that mistake and forget other essential elements that they are supposed to derive from the passage.

The impact of oral corrective feedback on learner's language skills is a phenomenon that can be assessed through various diverse ways. Applied linguistic researchers have carried out numerous studies aimed at establishing the impact of each of the oral corrective feedback strategies on the learning outcomes of the students. According to Pfanner (2015), application of corrective feedback in language lessons is one of the effective ways of ensuring that the learners develop a good foundation in learning the foreign language. Every language has the underlying structures that guide how it is spoken. For most languages, the alphabets act as the guiding elements which mainly influence the pronunciations of words. If a learner cannot correctly pronounce the alphabets in a given language, then it is less likely for them to master the language. Application of corrective feedback ensures that the learners grasp the fundamental concepts and build blocks of a given language. The approach used in correcting linguistic errors should only focus on certain types of errors. Some of the errors do not distort communication as they hardly change the meaning of the phrases or statements. Such mistakes should not be corrected as the learner self-corrects as they get a better knowledge of the language. The author classifies errors made in communication into global and local. Global errors are those that affect communication while local ones can easily be overlooked as they have little effect on communication. However, some teachers are unable to distinguish between local and global errors, and this makes them unable to figure out when they should apply oral corrective feedback strategies. This suggestion, however, focuses on the conversational element of oral corrective feedback and assumes its pedagogical significance in facilitating proper learning in languages.

In the classroom set up, the reactions of learners to feedback is used to assess the effectiveness of oral corrective feedback provided. The leading indicators that show the impact of such feedback are uptake, intake, and repair. In this context, it is expected that effective feedback should trigger the repair or correction of language mistakes. The ability of the learner to intake, process and implement corrective feedback shows their consciousness in noticing significant corrections (Bitchener, Young \& Cameron, 2005). In some cases, the learners fail to respond to corrections which make it impossible for the teacher to assess the effectiveness of the corrective feedback provided. As a result, most of the experimental studies conducted on the impact of oral corrective feedback on language skills of learners resort to comparing pre- and post-test scores.

Ineffective use of oral corrective feedback in language classes results in problems such as inconsistency, ambiguity, and ineffectiveness of teachers. Research has established that some of the teachers use unsystematic oral corrective feedback approaches that have a negative impact on the language skills of the students. Such feedbacks can be misleading as they do not focus on equipping the learner with appropriate language skills, but instead focus on supporting uninterrupted communication between the teacher and the learners (Zhao, 2015). Another problem that arises is that teachers at times ignore errors so as not to interrupt the communicative flow. Corrections' targeting a wide range of language learner error types overwhelms the students thus inhibiting the effectiveness of the oral corrective feedback given.

Conventionally, teachers play a critical role in triggering the development of self-correction skills in language 
learners. The oral corrective approach is considered the best approach that can be applied in language classes to facilitate effective learning. Notably, research conducted to establish the impact of oral corrective feedback on language skills reveals that indeed the effective application of the approach has a significant positive impact on the skills of the learner. The most fundamental impact of oral corrective feedback on language skills is that it enables the learner to realize their mistakes and facilitates self-correction. Overall, the oral corrective feedback has been tested and proven as one of the best approaches that should be extensively applied in language classes.

\section{MethodOLOGY}

The research methodologies used in the articles are mainly quantitative and qualitative design. A combination of these two approaches is believed to give more accurate results especially when the study is centered on an element that allows the application of the two research methods. The methodology primarily entails the use of experiments conducted in an actual classroom set up. The teachers in these experiments use various oral corrective feedbacks on the students and observe how the students react to such feedback. In other cases, especially where the research is keen on identifying the accurate impact of the feedback on language skills of the learners, a quantitative approach is used whereby the students are recorded as well as their performance in a specific language before and after oral corrective feedback. This approach gives authentic results and allows for a systematic evaluation of the effect of oral collective feedback on language learners.

The classroom-based research process is used to establish the effects of feedback in the formal class context. This strategy aims to find the effectiveness of the teachers in applying corrective feedback as well as the impact of such feedbacks on the learning process. The approach entails close observation and collection of data regarding the progress of the students. One of the key elements that this strategy focuses on is the response of the students to various feedbacks provided by the teachers. The researchers in the analyzed studies focus on the occurrence of corrections during language classes whereby most of the subjects are students undertaking courses in various languages. The studies mainly derive data regarding the occurrence of feedbacks and how the students implement such feedbacks to better their performance in a given language. Data collected from the experiments such as interview and observation records are analyzed to support the quantitative information obtained from these studies.

\section{Classification OF Studies}

The studies analyzed in this paper can be classified into several broad categories based on the research strategies applied to each. There are two broad categories of research approaches which are quantitative and qualitative. This paper utilizes studies that contain both qualitative and quantitative information regarding the impact of oral corrective feedback on language skills of a learner. The qualitative research studies used in this paper mainly expounds on the various types of feedbacks and how they impact on the performance of a student in languages (Solikhah, 2016). These type of studies do not analyze or compare any variables but simply narrate how the variable in the study is affected by the factors considered. Quantitative research is common in most of the articles used in this study. This entails the use of many samples as well as experimentation whereby the results are recorded and compared. Ideally, quantitative research approaches can further be divided into subgroups which include descriptive, correlational, quasi-experimental and experimental.

The articles used in this study apply all the quantitative research designs whereby the commonly used approach is the descriptive design which is focused on assessing the current status of the study phenomenon. The articles mainly assess the current state with regards to the use of oral corrective feedback in language classes. The researchers in these articles do not provide a hypothesis but generally explore the application of oral corrective feedback and its impact on the students' learning outcomes. Data collection is mostly observational. A number of studies use the correctional design which generally explores relationships between oral corrective feedback and learner language skills (Lyster, Saito \& Sato, 2013). These studies do not integrate details regarding cause and effects but only details how the pedagogical approach affects language classes. Quasi-Experimental Design is also used in some of the articles analyzed, and it explores the cause-effect relationships that exist between learner language skills and the application of oral corrective feedback. This approach entails the establishment of control groups which are compared with independent groups. A comparison of the results shows the impact of oral corrective feedback on the students.

Experimental designs are believed to be the best research designs for studying the variable phenomenon. This is mainly because they attempt to establish a relationship between the various variables involved in the study. It entails the use of independent and controlled variable whereby the researcher manipulates the controlled variables using the variables of the study. The independent groups are not manipulated and therefore provide results in a natural setting. The effects of the independent variable on the dependent variable are collected and analyzed for a relationship (Sobhani \& Tayebipour, 2015). In this study, the primary variables of study are the use of oral corrective feedback and its impact on language skills of the students. In this regard, the articles use a group of students who are exposed to the extensive use of oral corrective feedback while the other group undertakes language studies in the conventional classroom setting. The scores and language skills of the students from both groups are compared to reveal the effect of oral corrective feedback on the learning outcomes. 
The articles analyzed in this study make it clear that oral corrective feedback has a significant positive impact on the language skills of learners. Notably, provision of such feedback does not only enhance the spoken language, but it also plays a critical role in the development of written language and grammar skills in the learner. Language classes in higher grades are far much complicated compared to the classes of young children (Vilček, 2014). This is mainly because senior class language class involves going into details of the language structure, unlike children classes which mainly focus on pronunciations and spelling. This is the fundamental reason why senior language classes require the extensive use of the various types of feedbacks including oral corrective feedback. The complexity of the language influences the type and number of corrections made. It is, however, advisable that language teachers use minimal corrective feedback as many corrections may discourage the students and make them ignore vital corrections made in the future.

\section{CONCLUSION}

Feedback is extensively used as an evaluative approach that indicates the effectiveness of teaching strategies as well as the level of understanding of the students. Corrective feedback is used as a support strategy that improves the learning process especially in languages. Written and oral corrective feedbacks are the commonly used strategies whereby the oral approach corrects phonetic and pronunciation mistakes. Corrective feedback is essential as it helps teachers and learners to identify and focus on the common errors made in languages. Written corrective feedback is mainly used to correct grammar and spelling mistakes in language classes. Oral corrective feedback is an essential element in language classrooms. It provides a platform through which teachers can interact with students in a way that improves their language skills. Oral corrective feedback has several sub-divisions which are recast, repetition, clarification request, explicit correction, elicitation, and Para lingual signal. Each of these plays a critical role in the correction of learner mistakes in the classroom set up. Overall, oral corrective feedback has an extensive positive impact on the language skills of the learners.

\section{REFERENCES}

[1] Bitchener, J., Young, S., \& Cameron, D. (2005). The effect of different types of corrective feedback on ESL student writing. Journal of second language writing, 14(3), 191-205.

[2] Ellis, R. (2010). Epilogue: A framework for investigating oral and written corrective feedback. Studies in Second Language Acquisition, 32(2), 335-349.

[3] Han, Z. (2002). A study of the impact of recasts on tense consistency in L2 output. TESOL Quarterly, 36(4), 543-572.

[4] Loewen, S., \& Erlam, R. (2006). Corrective feedback in the chatroom: An experimental study. Computer Assisted Language Learning, 19(1), 1-14.

[5] Lyster, R., Saito, K., \& Sato, M. (2013). Oral corrective feedback in second language classrooms. Language teaching, 46(1), 140.

[6] Mendez, E., Arguelles, L., \& Castro, A. (2010). Oral corrective feedback: Some ways to go about it. FEL International, 33(1), 254-270.

[7] Penning de Vries, B. W. F., Cucchiarini, C., Strik, H., \& van Hout, R. W. N. M. (2010). The Role of Corrective Feedback in Second Language Learning: New Research Possibilities by Combining CALL and Speech Technology, Proceedings of SlaTE 2010, Tokyo, Japan

[8] Pfanner, N. I. (2015). Teacher Corrective Oral Feedback in the Classroom. 34(2). 46-55

[9] Phillips, E. M. (1992). The effects of language anxiety on students' oral test performance and attitudes. The modern language Journal, 76(1), 14-26.

[10] Sanavi, R. V., \& Nemati, M. (2014). The Effect of Six Different Corrective Feedback Strategies on Iranian English Language Learners' IELTS Writing Task 2. SAGE Open, 4(2), 2158244014538271.

[11] Sermsook, K., Liamnimitr, J., \& Pochakorn, R. (2017). The Impact of Teacher Corrective Feedback on EFL Student Writers' Grammatical Improvement. English Language Teaching, 10(10), 43-49.

[12] Sheen, Y. (2010). Differential effects of oral and written corrective feedback in the ESL classroom. Studies in Second Language Acquisition, 32(2), 203-234.

[13] Sheen, Y., \& Ellis, R. (2011). Corrective feedback in language teaching. Handbook of research in second language teaching and learning, 2, 593-610.

[14] Solikhah, I. (2016). Oral Corrective Feedback in Speaking Class of English Department. LINGUA: Journal of Language, Literature and Teaching, 13(1), 87-102.

[15] Sobhani, M., \& Tayebipour, F. (2015). The effects of oral vs. written corrective feedback on Iranian EFL learners' essay writing. Theory and Practice in Language Studies, 5(8), 1601-1611.

[16] Vilček, I. (2014). Oral Corrective Feedback in EFL: Teachers Techniques and Learners Attitude (Doctoral dissertation, Josip Juraj Strossmayer University of Osijek. Faculty of Humanities and Social Sciences.).

[17] Zhao, W. (2015). Learners' Preferences for Oral Corrective Feedback and Their Effects on Second Language Noticing and Learning Motivation (Doctoral dissertation, McGill University Libraries). 
Radiah Alsolami is a Lecturer in English Language department at Najran University Kingdom of Saudi Arabia. She has Educated in USA and KSA as an applied linguist, and has been involved in English language teaching before five years ago and has worked in various cultural contexts. She has taught writing, Grammar, Reading and Practicum teaching for the students of bachelors level. while teaching Practicum teaching, She has visited many schools to guide and observe the students of bachelor' level and it was a great experience to interact with different level of English Language learners. Her research areas include cognition and language, thinking skills, interaction and technology. 